\title{
UNIDADES DE CONSERVAÇÃO EM TERRAS DE USO DA UNIÃO: SUBSÍDIOS À IMPLANTAÇÃO DO PARQUE NATURAL MUNICIPAL CANTO DO MORCEGO, ITAJAÍ/SANTA CATARINA
}

\author{
ZIMMERMANN, C. E. ${ }^{12 *}$; SILVA JUNIOR, L. A. S. ${ }^{2}$; GOMES, R. T. D.'; CECCATO, M. W..; \\ SCHROEDER, R. ${ }^{2}$; DAMBROWSKI, V. ${ }^{2}$; CHRISTOFIDIS, M. ${ }^{3}$; POLETTE, M. ${ }^{2}$ \& MARENZI, R. C.. ${ }^{2}$
}

1. Laboratório de Ecologia e Ornitologia - FURB.

2. Escola do Mar, Ciência e Tecnologia - UNIVALI.

3. Superintendência do Patrimônio da União em Santa Catarina - SPU/SC.

*Autor correspondente: cezimmer@furb.br

\begin{abstract}
Zimmermann, C. E., Silva Junior, L. A. S., Gomes, R. T. D., Ceccato, M. W., Schroeder, R., Dambrowski, V., Christofidis, M., Polette, M. \& Marenzi, R. C. (2020). Unidades de Conservação em Terras de Uso da União: subsídios à implantação do parque natural municipal Canto do Morcego, Itajaí/Santa Catarina. Braz. J. Aquat. Sci. Technol. 24(1). eISSN 1983-9057. DOI: 15927/bjast.v24n1. One of the main strategies and public policies for nature conservation worldwide is the creation of Protected Areas, named Conservation Units (UCs/PAs) in Brazil. This study aims to identify how public federal areas affected by lighthouses conceded by the Federal Union Patrimony Secretariat of Brazil (SPU) to the Brazilian Military, in Santa Catarina State, are considered in the Protected Area Management Plans as a form of subsidy to the implementation of the Canto do Morcego Municipal Natural Park, in Itajaí. A survey was conducted with SPU and that lead to the research through institutional documents. Also interviews were taken with the Port of Itajai Authority and environmental agencies. The research included 5 Protected Areas with the presence of the Military in Santa Catarina, and 2 in other states. The PAs Management plans include the military areas, as well as the definition of specific management measures for these areas. When a military area is in the Protected area vicinity, zoning prevails as Conflicting Use Zone (ZUC). This fact occurs not because a conflict exists, but because the objectives of the military areas are not compatible with the primary goal of PAs. Partnerships between authorities of both Military and Protected Area was verified in all situations, even if the affected area is within the Buffer Zone. Partnerships collaborate importantly regarding many issues such as access, maintenance, and supervision, either from the PA or the lighthouses. Also, lighthouses turn out to be attractive to the public that usually visits Protected Areas. These information contributed to define that in the Park Zoning of Canto do Morcego it's positive to implement a cooperative management between the Municipal Itajaí environmental agency and Federal Governmental entities, constituting a specific zone ( ZUC) in the Lighthouse area, with indirect visitation.
\end{abstract}

Key Words: Lighthouse; Public Use, Conflict Management, Coastal management.

Unidades de Conservação (UCs) são espaços naturais legalmente protegidos com diferentes objetivos deacordocomacategoriademanejo. Sãoosinstrumentos estratégicos mais importantes no que se refere à proteção do patrimônio ambiental e sociocultural (Masullo et al., 2018). Unidades de Conservação tem sua gestão através do seu Plano de Manejo, entendido como um documento técnico mediante o qual são determinados o seu zoneamento e normas que devem presidir o uso da área e o manejo dos recursos naturais, de acordo com os objetivos gerais de cada categoria de unidade de conservação, inclusive a implantação das estruturas físicas necessárias à gestão (BRASIL, 2000). Com a experiência prática fornecida pela aplicação das diretrizes doPlano de Manejo pelos gestores da Unidade, este deve revisto periodicamente e incorporar novas informações, técnica e cientificamente comprovadas de aprimoramento para o manejo da UC (Galante et al., 2002).

A definição de zoneamento e de normas de condutanos Planos de Manejoincluemosobjetivos de uso público, que se refere a prática de visitação com objetivos educativos, esportivos, recreativos, científicos e de interpretação ambiental, que dão ao visitante a oportunidade de conhecer, entender e valorizar os recursos naturais e culturais existentes (Vallejo, 2013). O uso público pode ser aplicado a muitas categorias de UCs, mas, é comumente exercido em Parques, pois, os mesmos têm explícitos em seus objetivos as atividades de educação e interpretação ambiental, de recreação em contato com a natureza e de turismo ecológico (BRASIL, 2000).

Historicamente algumas unidades de conservação foram criadas em áreas onde já incidiam usos das Forças Armadas Brasileiras ou essas se instalaram em Unidades de Conservação já criadas. É caso do Parque Nacional de São Joaquim, criado em 06 de julho de 1961, em Santa Catarina (BRASIL, 1961). No ano de 1982 o Ministério da Aeronáutica adquiriu terras junto ao Morro da Igreja e da Pedra Furada, e implantou no ponto cênico e geológico mais atraente do Parque, um sistema de radares para controle do espaço aéreo, o Cindacta II (ICMBio, 2019).

Geralmente os objetivos da Unidade de Conservação difere dos objetivos das Forças Armadas 
Brasileiras, o que gera uma região na UC caracterizada como zona conflitante, ou seja, na elaboração do plano de manejo, especificamente no zoneamento daUC, estas áreas com sobreposição de interesses são denominadas Zona de Uso Conflitante (ZUC). Esse fato ocorre não porque existe um conflito, mas, pelo motivo dos objetivos de uso das áreas militares terem funções incompatíveis com os objetivos destas áreas protegidas.

Em implantação na cidade de Itajaí-SC o Parque Natural Municipal Canto do Morcego, cumprindo uma exigência de um Termo de Acordo Judicial (TAJ) entre a Prefeitura, a Fundação de Meio Ambiente de Itajaí (FAMAI, atual ICS), Promotoria Estadual e empreendedor da região, atendendo ao anseio da população local e turistas que têm interesse em visitar a região do promontório costeiro e a praia da Solidão (Belino et al., 2018). Atualmente a visitação é impedida pela Marinha do Brasil, que tem cessão especial de uso da Secretaria do Patrimônio da União (SPU) com fins de manter um Farol e estrutura de moradia para vigilância e de lazer de funcionários em parte da região que compõe a futura UC.

O Farol de Cabeçudas, localizado no Morro Cavaleiro da Ponta (Ferrari, 2009), foi incorporado à Marinha do Brasil através de uma concessão pelo sistema de gerenciamento dos Imóveis de Uso Especial da União, pela Portaria $n^{\circ} 327$ de 12/08/1980 que durou até o ano de 2015, mas que continua reconhecida (SPU/SC). Aregião em questão apresenta conflito de uso deste espaço, uma vez que o objetivo fundamental do Parque é a preservação do ecossistema e beleza cênica, conciliando ao uso público, o que difere dos interesses da Marinha do Brasil que trata de assegurar a navegação através da manutenção das atividades do Farol.

No intuito de fornecer subsídios para a elaboração do plano de manejo e zoneamento do futuro Parque, o objetivo deste estudo foi identificar como são tratadas nos planos de manejo e seus respectivos zoneamentos as áreas com cessão de uso às Forças Armadas Brasileiras, em especial em Santa Catarina e à
Marinha do Brasil a fim de definir estratégias de gestão para o Parque Natural Municipal do Canto do Morcego. A presença de um Farol foi avaliada e confrontada com outras unidades de conservação em diferentes regiões brasileiras que apresentam situações semelhantes: área militar $\mathrm{x}$ uso público.

O trabalho desenvolvido seguiu os preceitos do estudo exploratório com pesquisa bibliográfica a partir de materiais publicados (Gil, 2008), assim como, pesquisa documental por meio de consulta à Secretaria do Patrimônio da União (SPU) e aos sites do Instituto Chico Mendes de Conservação da Biodiversidade (ICMBio) e do Instituto de Meio Ambiente (IMA), para busca de dados e planos de manejo das Unidades de Conservação, além de consultas aos sites do Instituto Ambiental do Paraná (IAP) e Secretaria de Meio Ambiente (SEMA) do RS.

Nas Unidades de Conservação com presença das Forças Armadas, verificou-se a existência de planos de manejo e a inserção das áreas militares em seu zoneamento. Nas áreas estratégicas de gestão, a existência de faróis e outras estruturas das Forças Armadas, assim como a definição de medidas de manejo específicas para as áreas de cessão da SPU foram consideradas. Também foi realizada uma entrevista aberta com representante da Delegacia da Capitania dos Portos em Itajaí e uma visita acompanhada ao Farol e à área sob gestão da Marinha sobreposta pelo Parque Canto do Morcego.

Santa Catarina possui dezesseis Unidades de Conservação federais, dez estaduais e ainda sessenta e cinco Unidade municipais implantadas. Dentre as federais oito pertencem ao grupo Proteção Integral e oito ao grupo Uso Sustentável (Martins et al., 2015). A sobreposição com áreas de cessão do SPU para uso das Forças Armadas do Brasil acontece em cinco Unidades de Conservação federais. Também foram levantados dados de duas UCs federais e duas UCs estaduais, com sobreposição de competências administrativas em outros estados (Tabela 1).

Tabela 1 - Dados dos Planos de Manejo das respectivas UCs e/ou informações disponíveis nos órgãos gestores. ZUC - Zona de Uso Conflitante. ZUEsp - Zona de Uso Especial. ZUEx - Zona de Uso Extensivo. ZUIn - Zona de Uso Intensivo. ZA - Zona de Amortecimento. AExc - Área de Exclusão.

\begin{tabular}{|c|c|c|c|c|c|c|c|}
\hline Estado & UCs & Uso Conflito & $\begin{array}{c}\text { Plano de } \\
\text { Manejo/ano }\end{array}$ & $\begin{array}{l}\text { Inserção da } \\
\text { Área Militar }\end{array}$ & Inserção no Zoneamento & Condição do Patrimônio & Regime \\
\hline SC & $\begin{array}{l}\text { APA Baleia } \\
\text { Franca }\end{array}$ & $\begin{array}{l}\text { Marinha / Farol/Faroletes/ } \\
\text { Outras Instalacões }\end{array}$ & 2018 & Dentro da UC & $\begin{array}{c}\text { Zona Divergente/ } \\
\text { Zona de Conservacão }\end{array}$ & Ativo & Não informado \\
\hline SC & $\begin{array}{c}\text { APA } \\
\text { Anhatomirim }\end{array}$ & $\begin{array}{l}\text { Marinha / Fortaleza / } \\
\text { Farolete }\end{array}$ & 2013 & Dentro da UC & $\begin{array}{c}\text { Zona Terrestre de Proteção da Pesca } \\
\text { Artesanal }\end{array}$ & Tombado & Concessão \\
\hline $\mathrm{SC}$ & $\begin{array}{l}\text { REBIO Marinha } \\
\text { do Arvoredo }\end{array}$ & $\begin{array}{l}\text { Marinha / Farol / } \\
\text { Faroletes / Outras } \\
\text { Instalações }\end{array}$ & 2004 & $\begin{array}{c}\text { Fora da UC } \\
(\mathrm{AExC})\end{array}$ & $\begin{array}{c}\text { ZA - Farol / Outras Instalações } \\
\text { ZUC - Faroletes }\end{array}$ & Ativo & Parceria (cessão de estrutura/energia) \\
\hline SC & $\begin{array}{l}\text { PARNA São } \\
\text { Joaquim }\end{array}$ & Aeronáutica / Cindacta II & 2018 & Dentro da UC & ZUC - Aeronáutica & Ativo & Parceria (em processo) \\
\hline SC & $\begin{array}{l}\text { PARNA Serra do } \\
\text { Itajaí }\end{array}$ & $\begin{array}{l}\text { Exército / } 23^{\circ} \text { Batalhão de } \\
\text { Infantaria de Blumenau }\end{array}$ & 2009 & $\begin{array}{c}\text { Fora da UC } \\
\text { (AExc) }\end{array}$ & $\begin{array}{c}\text { ZA - Base Militar } \\
\text { ZUEx e UEsp - Acesso a Base Militar }\end{array}$ & Ativo & Cooperação \\
\hline $\mathrm{RN}$ & $\begin{array}{l}\text { REBIO Atol das } \\
\text { Rocas }\end{array}$ & Marinha / Farol & 2007 & Dentro da UC & ZUC & Ruínas antigo Farol / Ativo - Farol & Cooperação \\
\hline BA & $\begin{array}{l}\text { PARNA Marinho } \\
\text { de Abrolhos }\end{array}$ & Marinha / Farol & 1991 & $\begin{array}{l}\text { Fora da UC } \\
\quad(A E x c)\end{array}$ & ZA & Ativo & Cooperação \\
\hline PR & $\begin{array}{l}\text { PEST llha do } \\
\text { Mel }\end{array}$ & $\begin{array}{l}\text { Marinha / Faróis / } \\
\text { Farolete / Fortaleza }\end{array}$ & 2012 & $\begin{array}{l}\text { Dentro da UC } \\
\text { e fora (AExc) }\end{array}$ & $\begin{array}{c}\text { ZA - Farol das Conchas, Farolete e } \\
\text { Fortaleza } \\
\text { ZUC - Farol de Caraguatá }\end{array}$ & $\begin{array}{l}\text { Tombados - Farol das Conchas } \\
\text { (ativo), Farolete (ativo) e Fortaleza } \\
\text { / Ativo - Farol de Caraguatá }\end{array}$ & $\begin{array}{l}\text { Gestão Compartilhada: parte da llha } \\
\text { SPU/ Marinha do Brasil e Parte cessão } \\
\text { para o Órgão Gestor }\end{array}$ \\
\hline RS & PEST de Itapuã & Marinha / Farol & 1998 & Dentro da UC & ZUln - Farol de Itapuã & Ativo & Protocolo de intenção ou Convênio \\
\hline
\end{tabular}


A partir das análises dos planos de manejo (Tabela 1), verificou-se que há casos em que as Forças Armadas estão inseridas fora do limite da UC, mas, no perímetro dessa, constituindo uma área vazada na delimitação, sendo nesse trabalho denominada de Área de Exclusão (AExc). Há situações em que a Base Militar ou Farol está nos limites externos da UC ou na sua Zona de Amortecimento, definida como "o entorno de uma unidade de conservação, onde as atividades humanas estão sujeitas a normas e restrições específicas, com o propósito de minimizar os impactos negativos sobre a unidade" (BRASIL, 2000: Art. 10).

Nas demais situações inseridas no interior da UC os casos levantados indicam que as Forças Armadas incidemsobreas seguinteszonas: 1)ZonadeUsoEspecial (ZEsp) - contém áreas necessárias à administração, manutenção e/ou serviços da Unidade; 2) Zona de Uso Extensivo (ZUEx) - predominam áreas naturais, podendo apresentar alguma alteração humana, com o objetivo de manejo e manutenção de um ambiente natural com mínimo impacto humano garantindo o uso público e a visitação controlada de trilhas e atrativos naturais; 3) Zona de Uso Intensivo (ZUIn) - constituída por áreas naturais ou antropizadas em que o ambiente é mantido o mais próximo possível do natural, abriga a estrutura de visitação como centro de visitantes, outras facilidades e serviços para o uso público; 4) Zona de Uso Conflitante (ZUC) - são espaços estabelecidos na unidade antes da criação, cujos usos e finalidades conflitam com o objetivo de conservação da área protegida, objetivando regularizar a situação conflituosa ou readequar o uso (Galante et al., 2002).

Nas Unidades de Conservação de SC em que há sobreposição na gestão da UC com as Forças Armadas, tem-se: Marinha na Área de Proteção Ambiental (APA) Baleia Franca, APA Anhatomirim e Reserva Biológica (REBIO) Marinha do Arvoredo; Exército no Parque Nacional (PARNA) Serra do Itajaí; e Aeronáutica no PARNA São Joaquim. Com exceção da APA Baleia Franca, cujo plano de manejo não informa, nas demais foi verificado algum tipo de parceria entre as partes, principalmente em função de acesso, manutenção e fiscalização.

Em relação às UCs com estruturas da Marinha conflitando com os seus objetivos, temos a APA Anhatomirim onde ocorre a cessão de direito do SPU para a UC. Na REBIO Marinha do Arvoredo ocorre uma parceria entre a Marinha e a gestão da UC, sendo que a área do Farol está em Área de Exclusão, situada neste caso na Zona de Amortecimento, além de dois Faroletes inseridos no interior da UC, e neste caso, a Marinha cede estruturas e energia elétrica para a UC. Para a APA Baleia Franca, as estruturas estão sobre gestão da Marinha, o Zoneamento não é específico para as áreas em sobreposição, acompanha o Zoneamento de outros interesses da APA, não foram encontradas no plano sobre alguma parceria de gestão das áreas.

Nos casos dos Parques Nacionais Serra do Itajaí e São Joaquim, as áreas militares estão localizadas no interior das UCs e o acesso a elas percorre trechos das unidades, de forma que a manutenção do acesso é de responsabilidade conjunta das instituições gestoras, Aeronáutica/Exército e Chefia dos PARNA. A gestão do PARNA São Joaquim prevê a elaboração de um termo de parceria com o Cindacta II, que segundo informação do chefe do Parque (Michel Tadeu Rodrigues Nolasco de Omena, 2018), com a implantação da base da Aeronáutica a gestão cooperativa das entidades sempre foi necessária, funcionando de forma relativamente eficiente, dependendo do Comandante do Cindacta. Contudo, no Morro da Igreja, base do Cindacta II, com o melhor ponto de observação para a Pedra Furada, recebeu aproximadamente 119.000 visitantes em 2017, colocando este Parque Nacional em posição de destaque entre os mais visitados (ICMBio, 2019).

No plano de manejo do PARNA Serra do Itajaí, a Base do Exército está no interior do Parque, mas, em uma Área de Exclusão (AExc) e outra área localizada na Zona de Amortecimento, com o acesso percorrendo o interior do Parque. Nas duas situações existe um regramento para uso das áreas pelo Exército, sendo que nos dois PARNAS, Itajaí e São Joaquim, os acessos as áreas das Forças Armadas são restritos.

Nas demais UCs federais pesquisadas, como na REBIO Atol das Rocas a área de uso da Marinha está inserida na UC e no PARNA Marinho de Abrolhos está na ZExc, sendo verificado em ambos os planos de manejo a necessidade da parceria com a Marinha para a fiscalização (ICMBio, 2007; Krob, 2003). Na REBIO Atol das Rocas a presença da Marinha do Brasil na ilha do Farol é considerada conflitante com os objetivos de criação da UC, mas, a existência desta estrutura é de fundamental importância para a segurança da navegação e do próprio atol, evitando que embarcações se choquem com o recife.

Contudo, isto não exime, em termos conceituais e para fins de zoneamento, de categorizar o Farol como em uma ZUC, bem como, não significa a necessidade de se tomar qualquer medida no sentido da retirada das estruturas. Este Farol consiste em uma área de $100 \mathrm{~m}^{2}$, possuindo um regramento a fim de minimizar impactos relativos a presença e manutenção dessa estrutura. A Marinha do Brasil, através da Capitania dos Portos da cidade de Natal tem auxiliado na fiscalização da UC quando solicitada, mas não há um convênio estabelecido para uma fiscalização sistemática e ostensiva. 
No PARNA de Abrolhos a área de ocupação da Marinha Brasileira se concentra na ilha de Santa Bárbara, e serve como ponto de apoio e socorro às embarcações que estejam navegando na região. As atividades ali desenvolvidas causam algum impacto, principalmente pelo lançamento de âncora sobre o fundo de coral e pela geração de poluentes. Contudo, apesar da llha de Santa Bárbara não estar inserida no Parque é proposto o uso público em função de ser de interesse à visitação e gestão do Parque.

Quanto as unidades de conservação estaduais pesquisadas, ambas contêm estruturas militares em seus limites, sob uso da Marinha. No Parque Estadual (PEST) Ilha do Mel há presença de um Farol, um Farolete e uma Fortaleza (Forte), abertos à visitação pública como importantes atrativos turísticos e incluídos em Zona de Uso Conflitante. No PEST de Itapuã, o Farol se insere no interior da UC e dento da Zona de Uso Intensivo, portanto, de uso público. Importante destacar que o Plano de Manejo deste Parque é de 1996, período que ainda não havia sido publicado o roteiro metodológico para planejamento de Parque Nacional, Reserva Biológica e Estação Ecológica, em que foi conceituada a Zona de Uso Conflitante (Galante et al., 2002) e, adotada para demais categorias de UCs. Contudo, os zoneamentos dos planos de manejo do PARNA Serra do Itajaí, das APAs Anhatomirim e Baleia Franca não adotaram essa ZUC, mesmo que os seus planos elaborados mais recentemente, 2009, 2013 e 2018, respectivamente.

Todas as UCs levantadas foram criadas quando já havia presença das Forças Armadas nos espaços que passaram a ser áreas legalmente protegidas, com exceção do PARNASão Joaquim, em que a presença do Cindacta Il ocorreu 21 anos após a criação do Parque.

Além das UCs levantadas, cabe destacar o Refúgio de Vida Silvestre de Alcatrazes, criado em 2016, numa área que era usada como teste de tiro de canhão da Armada. Nesta UC, já foi elaborado Plano de Manejo, em que no Programa de Administração e Operacionalização, uma das atividades é "Estabelecer Acordo de Cooperação com a Marinha, que indicará um protocolo para manutenção das instalações militares, obrigações gerais das partes, acompanhamento e mitigação dos impactos dos exercícios militares no arquipélago dos Alcatrazes, monitoramento ambiental e o comitê de acompanhamento da execução das ações previstas" (ICMBIO, 2017a).

Um novo tipo de zona foi estabelecido para incluir as instalações da Marinha, Zona de Compatibilização de Usos, que tem como definição "áreas naturais podendo apresentar antropização, sendo sujeitas a alterações definidas no Artigo 13, parágrafos $2^{\circ} \mathrm{e}$ $3^{\circ}$ da Lei do SNUC - Sistema Nacional de Unidades de Conservação (Lei no 9.985, de 18 de julho de
2000), compatibilizando os objetivos da unidade de conservação com a utilização da terra e dos recursos naturais" (ICMBio, 2017a). Nesta UC também já foi desenvolvido Plano de Uso Público (ICMBio, 2017b).

Foram identificadas junto à SPU de Santa Catarina 27 Faróis ou Faroletes em terras da União, distribuídos em nove municípios com algum regime de cessão para a Marinha do Brasil, sendo: Araranguá (1), Sombrio (1), Laguna (5), Imbituba (2), Palhoça (2), Itajaí (3), Penha (1) e São Francisco (5), todos de competência da Delegacia dos Portos-Marinha do Brasil. Dentre os faróis identificados estão em sobreposição com Unidades de Conservação, conforme a SPU, cinco faróis em Laguna e um em Imbituba, que se sobrepõem a APA Baleia Franca, e dois faróis em Florianópolis que estão em áreas da APA de Anhatomirim e da REBIO do Arvoredo, respectivamente (Tabela 1). Dos três faróis identificados em Itajaí, apenas o Farol de Cabeçudas está na área de criação do Parque Natural Municipal da Orla de Itajaí. Estes locais onde estão instalados os faróis, normalmente promontórios costeiros, se destacam para contemplação da paisagem (Oliveira et al., 2018), atividade de uso público em caso de Unidades de conservação.

O Farol de Cabeçudas ocupa parte de um terreno de $176.220 \mathrm{~m}^{2}$ (17,62 ha) e apresenta $355,30 \mathrm{~m}^{2}$ de área construída, onde está localizada a casa do Faroleiro com $60 \mathrm{~m}^{2}$ e a estrutura de lazer dos funcionários da Delegacia dos Portos em Itajaí com $55 \mathrm{~m}^{2}$ (Ferrari, 2009). Atualmente o Farol é hiper-radiante, com duas lâmpadas halogênicas acopladas a outros equipamentos (Ferrari, 2009), o que conforme a Capitania dos Portos de Itajaí, garante a navegação segura na região, especialmente o acesso ao Porto de Itajaí, e sendo a Marinha do Brasil responsável pela manutenção deste. Assim cabe a ela condicionar as limitações de uso do espaço, no que diz respeito à necessidade de conservação relacionada à sua área de concessão.

$O$ regime de concessão de que trata a área do Farol de Cabeçudas cedida à Marinha do Brasil é de 'Entrega', e conforme a SPU está regulamentado pelo Decreto-Lei n ${ }^{\circ} 9.760$ de 05/09/1946 e Decreto $n^{\circ} 3.725$ de 10/01/2001, que regulamenta a entrega de imóvel para uso da Administração Pública Federal direta e indireta. Este regime de Entrega do Farol data de início de 1982, finalizando em 2015, mas ainda em uso.

A proposta de implantação do Parque Natural Municipal do Canto do Morcego em cumprimento ao Termo de Acordo Judicial (TAJ) busca atender o anseio da população local e de turistas que almejam adentrar no promontório onde está inserido o Farol de Cabeçudas, considerando a atributo paisagístico da região (Belino et al., 2018). Contudo, a Marinha impede o acesso, uma vez que não existe estrutura 
e segurança para os visitantes e segurança para a própria estrutura física do Farol. Em visita em campo, foi confirmado o potencial de visitação pública, especialmente decorrente da beleza cênica representada pelo conjunto de elementos da vegetação costeira, de costão rochoso de pequena enseada (praia da Solidão) e do contraste da urbanização ao longe, caracterizando uma paisagem natural-cultural. Contudo também foi observada a falta de Infraestruturas de segurança, como passarelas e decks, devido à altura da costa e a situação de erosão existente, especialmente nos caminhos já abertos.

Oliveira \& Nicolodi (2012) chamam a atenção para o documento elaborado em 2004 pelo Grupo Interministerial (18 instituições), sobre a Gestão do Patrimônio da União tendo como uma das diretrizes a de trabalhar os conflitos entre a SPU e as Prefeituras Municipais para que alcancem um objetivo comum, como aqui, para propiciar a visitação no promontório em que está instalado o Farol de Cabeçudas, uma vez em que há concessão pela SPU à Marinha e onde se quer implantar o Parque a ser gerenciado pelo órgão ambiental municipal. Neste sentido, Ferrari (2009) propôs a criação de uma UC para a proteção do promontório do Farol de Cabeçudas, indicando parcerias entre a Marinha, representada pela Delegacia de Capitania dos Portos de Itajaí e a Prefeitura, buscando uma gestão participativa da área.

Este trabalho não identificou parceria entre a União e Prefeituras na gestão de UCs, mas levantou casos de UCs federais e estaduais, especialmente localizadas em áreas que há cessão de uso da Marinha do Brasil, demostrando a possibilidade de gestão compartilhada, inclusive a maioria inserindo a área militar dentro da Zona de Uso Conflitante. No caso do Parque Canto do Morcego, mesmo sem ato de criação legal, já foi elaborado seu Plano de Manejo, também previsto no TAJ. Neste, a área do Farol de Cabeçudas ficou estabelecida como Zona de Uso Conflitante, pois, a estrutura do farol tem objetivos de uso incompatíveis com os objetivos da UC, sendo necessário $o$ isolamento da estrutura militar, mas, ao mesmo tempo estimulando o desenvolvimento de interpretação ambiental voltada ao Farol (função, história, etc.) e o acesso controlado a praia passando pela área de cessão de uso da Marinha.

Houve representatividade da Marinha na elaboração do Plano de Manejo do Parque Canto do Morcego, o que remete a potencialidade de cooperação entre os entes de diferentes esferas públicas, podendo ser pioneira neste tipo de gestão compartilhada.

O levantamento realizado neste trabalho não encerra a possibilidade de demais unidades de conservação com presença em áreas de cessão de concessão de uso das Forças Armadas do Brasil, mas, já foi possível constatar a possibilidade de parceria para uma gestão compartilhada, prevalecendo os objetivos de proteção da biodiversidade, conciliada, dependendo da categoria, ao uso público para a visitação com fins de interpretação e educação ambiental e recreação em contato com a natureza.

\section{REFERÊNCIAS}

Belino, J.A.; Beltrão, A. \& Marenzi, R.C. 2018. Análise da qualidade visual da paisagem de praias arenosas na orla de Itajaí-SC. Braz. J. Aq. Sci. and tech. 21(2): 19-25.

BRASIL, 2000. Lei no 9.985 de 18 de julho de 2000. Institui o Sistema Nacional de Unidades de Conservação e dá outras providências. Brasília: $16 p$.

BRASIL, Decreto $n^{\circ} 50.922$, de julho de 1961. Cria o Parque Nacional de São Joaquim (P.N.S.J.) no Estado de Santa Catarina, e dá outras providências. Brasília: $2 p$.

BRASIL, Decreto $n^{\circ} 3.725$, de 10 de janeiro de 2001. Regulamenta a Lei no 9.636 , de 15 de maio de 1998, que dispõe sobre a regularização, administração, aforamento e alienação de bens imóveis de domínio da União, e dá outras providências. Brasília.

BRASIL, Decreto $n^{\circ} 9.760$, de 5 de setembro de 1946. Cria o Parque Nacional de São Joaquim (P.N.S.J.) no Estado de Santa Catarina, e dá outras providências. Dispõe sobre os bens imóveis da União e dá outras providências. Brasília.

Ferrari, M. Di R. 2009. Análise do processo de conservação do Promontório do Farol -Itajaí/SC. Avaliação ecológica rápida (AER). Monografia de Graduação. UNIVALI, Itajaí. 88p.

Galante, M.L.V.; Bessera, M.M.L. \& Menezes, E.O. 2002. Roteiro metodológico de planejamento: parque nacional, reserva ecológica e estação ecológica. DIREC/CGEUC/COPUC. Brasília: IBAMA, $136 \mathrm{p}$.

Gil, A.C. 2008. Métodos e Técnicas de Pesquisa Social. $6^{\circ}$ ed. São Paulo: Atlas. 220p.

IAP, 2012. Instituto Ambiental do Paraná. Plano de Manejo do Parque Estadual da Ilha do Mel. Governo do Paraná.

IBAMA, 1991. Instituto Brasileiro de Meio Ambiente. Plano de Manejo do Parque Nacional Marinho dos Abrolhos. Brasília: Ministério do Meio Ambiente.

IBAMA, 2004. Instituto Brasileiro de Meio Ambiente. Plano de Manejo da Reserva Biológica Marinha do Arvoredo. Brasília: Ministério do Meio Ambiente - MMA. 
ICMBio, 2007. Instituto Chico Mendes de Conservação da Biodiversidade. Plano de Manejo da Reserva Biológica do Atol das Rocas. Brasília: MMA.

ICMBio, 2009. Instituto Chico Mendes de Conservação da Biodiversidade. Plano de Manejo do Parque Nacional Serra do Itajaí. Brasília: MMA.

ICMBio. 2013. Instituto Chico Mendes de Conservação da Biodiversidade. Plano de Manejo da Área de Proteção Ambiental Anhatomirim. Brasília: MMA.

ICMBIO, 2017a. Instituto Chico Mendes de Conservação da Biodiversidade. Plano de Manejo da Estação Ecológica Tupinambás e do Refúgio de Vida Silvestre do Arquipélago de Alcatrazes. Brasília: MMA. V2.

ICMBIO, 2017b. Instituto Chico Mendes de Conservação da Biodiversidade. Plano de uso público do Refúgio de Vida Silvestre do Arquipélago de Alcatrazes. Brasília: MMA.

ICMBIO, 2018. Instituto Chico Mendes de Conservação da Biodiversidade. Plano de Manejo da Área de Proteção Ambiental Baleia Franca. Brasília: MMA.

ICMBIO, 2019. Instituto Chico Mendes de Conservação da Biodiversidade. Parque Nacional de São Joaquim. Disponível em: http://www.icmbio. gov. br/parnasaojoaquim/quem-somos/historia.html. Acesso em 5 de novembro de 2019.

Krob, A.J.D. 2003. Plano de uso público para o Parque Nacional Marinho dos Abrolhos. Instituto Brasileiro do Meio Ambiente e dos Recursos Naturais Renováveis - IBAMA. Ministério do Meio Ambiente - MMA. Brasília.

Martins, L.; Marenzi, R.C. \& Lima, A. 2015. Levantamento e representatividade das Unidades de Conservação instituídas no estado de Santa Catarina, Brasil. Desenvolvimento e Meio Ambiente. 33(1): 241-259.

Masullo, Y.A.G.; Gurgel, H. da C. \& Laques, A. E. 2018. O passado e o presente das unidades de conservação do Maranhão, Brasil. Caminhos de Geografia, Uberlândia, 19(66): 250-268.

Oliveira, C.; Marenzi, R.C. \& Longarete, C. 2018. Serviços ecossistêmicos prestados pelos promontórios costeiros no litoral centro-norte de Santa Catarina. Braz. J. Aq. Sci. and tech. 21(2): 10-18.

Oliveira, M.R.L. \& Nicolodi, J.L. 2012. A Gestão Costeira no Brasil e os dez anos do Projeto Orla. Uma análise sob a ótica do poder público. Revista da Gestão Costeira Integrada 12(1): 89-98.

Omena, M, T. R. N. Conflitos de gestão com área militar. Mensagem recebida por < vadambrowski@ gmail.com> em 4 de maio de 2018. Acesso em: 2018.
SAA, 1998. Secretaria da Agricultura e Abastecimento. Plano de Manejo do Parque Estadual de Itapuã. Governo do Rio Grande do Sul.

Vallejo, L.R. 2013. Uso público em áreas protegidas: atores, impactos, diretrizes de planejamento e gestão. Revista Eletrônica Uso Público em Unidades de Conservação. 1(1): 13-26.

Submetido: Setembro/19

Revisado: Julho/20

Aceito:Julho/20

Publicado: $27 / 08 / 2020$ 